\title{
SANEAMIENTO Y DETOXIFICACIÓN DE CARNE DE LLAMA (Lama glama) INFECTADA CON Sarcocystis aucheniae MEDIANTE MÉTODOS QUÍMICOS: MARINADO, AHUMADO, CURADO SECO Y CURADO HÚMEDO ${ }^{1}$
}

\author{
SANITATION AND DETOXIFICATION Of LAMA MEAT (LAMA GLAMA) INFECTED WITH SARCOCYSTIS \\ AUCHENIAE THROUGH CHEMICAL METHODS: MARINATED, SMOKED, DRY CURED AND \\ WET CURED
}

\author{
Lidia Granados Z. ${ }^{2}$, Miguel Vilca L. $^{3}$ y Rosa Sam T. ${ }^{4}$
}

\section{Resumen}

Se evaluó la capacidad de sanear y detoxificar la carne de llama con macroquistes de Sarcocystis aucheniae a través de los métodos químicos de marinado, ahumado, curado seco y curado húmedo. Además, se incluyó un grupo control positivo (carne sin tratar). Se preparó un lisado a partir de macroquistes provenientes de carnes tratadas y no tratadas, que fue inoculado en 30 conejos $(100 \mu \mathrm{g} / \mathrm{kg}$ de peso vivo en forma subcutánea). Los conejos del grupo curado húmedo y control positivo presentaron signos clínicos de toxicidad llegando a morir entre las 8 y 12 horas de la inoculación. Así mismo, 12 perros de 4-6 meses de edad recibieron la carne (150-200 macroquistes por animal) previamente tratada con uno de los métodos químicos bajo evaluación (un grupo de canes quedó como control positivo). Solamente los perros del grupo control eliminaron esporoquistes a partir del día 14 post-ingestión. Los resultados demuestran que los tratamientos marinado, ahumado y curado seco lograron sanear y detoxificar la carne de llama parasitada con Sarcocystis aucheniae.

Palabras clave: Sarcocystis aucheniae, macroquistes, carne, conejo, inóculo, perro, esporoquiste

\section{Abstract}

The sanitation and disinfecting of lama meat naturally infected with macrocysts of Sarcocystis aucheniae through any of four chemical methods (marinated, smoked, dry cured and wet cured) was evaluated. In addition, a positive control group (non-treated meat) was included. A lisis of macrocysts from treated and non-treated meats was prepared and inoculated into 30 rabbits ( $100 \mu \mathrm{g} / \mathrm{kg}$ of body weigh, subcutaneously). Rabbits of the humid cured and positive control groups showed clinical signs of toxicity and died within 8-12 hours post-inoculation. Furthermore, 12 puppies of 4-6 months of age were

\footnotetext{
${ }^{1}$ Estudio financiado por INCAGRO

${ }^{2}$ Práctica privada

${ }^{3}$ Laboratorio de Salud Pública y Saneamiento Ambiental, FMV-UNMSM

E-mail: mvilcal@unmsm.edu.pe

${ }^{4}$ Laboratorio de Microbiología y Parasitología Veterinaria, FMV-UNMSM
} 
fed with the infected lama meat (150-200 macrocysts per puppy) previously treated with one of the chemical methods under evaluation (one group was kept as a positive control one). Solely dogs of the positive control group eliminated sporocysts after 14 days of ingestion. The results showed that marinated, smoked and dry cured methods were able to clean and disinfect lama meat infected with macrocysts of Sarcocystis aucheniae.

Keys words: Sarcocystis aucheniae, macrocysts, meat, rabbits, dogs, sporocysts

\section{INTRODUCCIÓN}

Se estima que alrededor de 500 mil familias campesinas de la región andina dependen directamente de la actividad productiva de los camélidos sudamericanos (CSA). Los ingresos generados por estos productores varían entre 300 a 500 dólares por familia al año (MINAG, 2004); sin embargo, el bajo precio de la fibra de alpaca y de llama en el mercado limita ese ingreso, siendo necesario impulsar otros parámetros productivos de estas especies, como puede ser la producción de carne, a fin de mejorar la rentabilidad del sistema de producción.

La llama, entre las especies de CSA, tiene el mayor potencial para producción de carne (Leyva, 1989). Además, tiene un 58\% de rendimiento de canal (Bravo et al., 1981) en comparación con la alpaca cuyo rendimiento es de 52\% (Calderón et al., 1972); sin embargo, este potencial productivo se encuentra limitado por factores tales como la crianza en praderas alto andinas, que aportan una dieta pobre en cantidad y calidad, especialmente en la época seca, así como el hecho que la carne que se expende en los mercados proceda mayormente de animales adultos, que contienen un carga elevada de macroquistes de Sarcocystis aucheniae en la canal (Castro, 1974; Leguía et al., 1988). Este último problema demerita la calidad de la carne, afectando su precio en el mercado y en algunos casos ocasionando el decomiso de la canal (Vilca et al., 1996).
La sarcocystiosis es importante en la salud pública, debido a que el consumo de carne infectada en forma cruda o mal cocida puede producir un cuadro de gastroenteritis, principalmente en niños, con presencia de dolor estomacal, diarrea, escalofríos, náuseas y vómitos (Leguía et al., 1988), por la acción de sustancias tóxicas procedentes de los quistes. Una alternativa de solución a este problema es interrumpir el ciclo biológico del parásito asociado a la inactivación de la toxina (Hiepe et al., 1981). Es por ello que el propósito de este estudio fue inactivar la toxina de los quistes mediante la aplicación de tratamientos químicos a carnes de llamas afectadas por sarcocistiosis macróscopica, así como determinar la inocuidad del producto a través de pruebas biológicas con conejos y canes.

\section{Materiales y Métodos}

\section{Carne infectada con S. aucheniae}

La carne infectada con quistes de Sarcocystis aucheniae procedió de seis llamas adultas de ambos sexos del camal de la ciudad de Huancavelica. Se seleccionó el cuello de la canal por ser la zona corporal con mayor presencia de quistes. La carne fue fileteada en trozos de 15 a $20 \mathrm{~cm}$ de largo y de $0.5 \mathrm{~cm}$ de grosor y se distribuyó en cinco porciones con cantidades similares de quistes. 


\section{Grupos experimentales}

El estudio se realizó en los laboratorios de la FMV-UNMSM, en la ciudad de Lima. La carne fileteada con macroquistes de $S$. aucheniae fue distribuida al azar en cinco grupos experimentales:

- Grupo 1: Marinado. Cada $100 \mathrm{~g}$ de carne se trató con $200 \mathrm{ml}$ de vinagre $(5 \%$ de ácido acético) y $5 \mathrm{~g}$ de sal, y se guardó en refrigeración por 48 h. Luego se procedió a lavar la carne.

- Grupo 2: Ahumado. La carne se colocó en ahumador accionado con carbón y coronta seca, a $60^{\circ} \mathrm{C}$ y por $2 \mathrm{~h}$.

- Grupo 3: Curado seco. Se preparó una mezcla de $1 \mathrm{~kg}$ de sal $+1 \mathrm{~g}$ de nitrito +250 g de azúcar para cada $2 \mathrm{~kg}$ de carne. La carne se colocó en capas alternas con esta mezcla. Así mismo, se utilizó un contrapeso para facilitar el drenaje de líquido de la carne. Luego, la carne tratada se guardó en refrigeración por 10 días; pasado los cuales, se extrajo y se sumergió en agua potable y fría por $24 \mathrm{~h}$ para eliminar las sales.

- Grupo 4: Curado húmedo. Se preparó una mezcla a base de $1 \mathrm{~kg}$ de sal $+1.3 \mathrm{~g}$ de nitrito $+100 \mathrm{~g}$ de azúcar en 10 litros de agua hervida. Se sumergió $2 \mathrm{~kg}$ de carne en esta solución y se guardó en refrigeración por 10 días. Luego, la carne se extrajo, se lavó y se sumergió en agua potable y fría por $24 \mathrm{~h}$ para eliminar las sales.

- Grupo 5: Control. Carne cruda fresca no tratada.

\section{Letalidad de las toxinas de los macroquistes}

Se utilizaron 30 conejos de ambos sexos de 4-5 meses de edad, de raza Nueva Zelanda, para evaluar la letalidad de proteínas de macroquistes provenientes de carnes tratadas mediante métodos químicos. Se colocaron 5 conejos por jaula dentro de un mismo ambiente, donde permanecieron en cuarentena por 30 días. Las jaulas se limpiaron diariamente y los animales recibieron una alimentación a base de concentrado comercial, además de complejo B y agua ad libitum. Se registró el peso corporal de cada conejo para calcular la dosis del inóculo.

Para preparar el inóculo, se extrajeron los macroquistes de las carnes tratadas y no tratadas y se conservaron en solución salina fosfatada $0.15 \mathrm{M}$ ( $\mathrm{pH}$ 7.2). Luego, fueron machacados en un mortero, tamizados, sometidos a un ultrasonicador para lisar las membranas de los bradizoitos de los macroquistes, y finalmente, centrifugados. El sobrenadante fue el inóculo de proteínas no purificadas. La dosis de inóculo que se aplicó por conejo fue de $100 \mu \mathrm{g} / \mathrm{kg}$ de peso vivo, vía subcutánea. Al grupo control negativo se le aplicó suero fisiológico.

El efecto de la toxicidad se evaluó durante 27 h post-inoculación, registrándose los signos clínicos que presentaron los conejos (hiperemia, postración, pupila contraída, disnea, diarrea). Además, se registró la temperatura rectal previo al inóculo y luego 1, 4, 8 y 16 h post-inoculación. Los animales que murieron fueron necropsiados.

\section{Viabilidad de los macroquistes}

Se utilizó 12 cachorros caninos de 4-6 meses de edad de ambos sexos para evaluar la viabilidad de los macroquistes de las carnes tratadas con métodos químicos. Los cachorros fueron evaluados clínicamente y estuvieron en cuarentena por 30 días en caniles que se desinfectaban diariamente. Se les vacunó y controló los parásitos internos con un producto comercial a base de Fenbendazol y Praziquantel y los parásitos externos con Fipronil. Los animales recibieron un alimento balanceado comercial y agua ad limitum y se les mantuvo libres de contacto con otros animales y entre los grupos. 
Cuadro 1. Temperatura rectal promedio en conejos inoculados con proteínas de macroquistes lisados de Sarcocystis aucheniae provenientes de carne de llamas tratadas con métodos químicos

\begin{tabular}{lccccc}
\hline \multirow{2}{*}{ Método químico } & \multicolumn{5}{c}{ Temperatura rectal $\left({ }^{\circ} \mathrm{C}\right)$ post inoculación } \\
\cline { 2 - 6 } & $0 \mathrm{~h}$ & $1 \mathrm{~h}$ & $4 \mathrm{~h}$ & $8 \mathrm{~h}$ & $16 \mathrm{~h}$ \\
\hline Marinado & 39.2 & 39.4 & 40.1 & 41.2 & 39.3 \\
Ahumado & 38.7 & 39.2 & 40.0 & 40.7 & 38.7 \\
Curado seco & 38.8 & 39.0 & 40.0 & 40.9 & 39.3 \\
Curado húmedo & 38.6 & 39.5 & 40.7 & 39.7 & Murieron \\
Control positivo & 39.1 & 40.0 & 41.3 & 40.4 & Murieron \\
Control negativo & 38.4 & 38.6 & 39.0 & 39.6 & 38.9 \\
\hline
\end{tabular}

Los cachorros fueron distribuidos al azar en 6 grupos de 2 animales cada uno. Los cuatro primeros grupos consumieron la carne tratada con alguno de los cuatro métodos químicos bajo evaluación, y los dos últimos grupos quedaron como grupos controles. De estos últimos, un grupo consumió carne parasitada sin ningún tratamiento (control positivo) y el otro sólo consumió alimento comercial (control negativo). Cada porción de carne parasitada que se le proporcionó a cada animal tuvo aproximadamente entre 150 a 200 macroquistes.

El efecto del tratamiento se evaluó entre el día 9 al día 30 post-ingestión a través de la búsqueda diaria de esporoquistes en heces procesadas por el método de flotación con solución saturada de sal.

\section{Resultados}

Los conejos del grupo control positivo y del grupo curado húmedo presentaron signos clínicos de toxicidad (anorexia, diarrea, congestión conjuntiva, inestabilidad, ataxia y opistótomo, depresión, postración). Los demás grupos no presentaron signos clínicos. La variación de la temperatura rectal se muestra en el Cuadro 1.
El efecto letal de la proteína se observó en los animales del grupo control positivo y del curado húmedo, los cuales murieron entre las 8 y 12 h post-inoculación. En la necropsia se encontró congestión en hígado, pulmón, riñón, bazo y tráquea, hemorragia pulmonar, hidropericardio y gastritis severa con desprendimiento de mucosa.

En el análisis coprológico de los canes no se encontró esporoquistes con excepción del grupo control positivo, los cuales eliminaron esporoquistes a partir de los 14 días de la ingestión de la carne.

\section{Discusión}

Los resultados obtenidos en el estudio demuestran que existen diversos mecanismos capaces de inactivar las proteínas de los macroquistes de $S$. aucheniae en la carne de llama. La capacidad tóxica de los macroquistes reside en sus características proteicas, las cuales se pierden cuando la proteína se altera, ya sea estructuralmente en su forma, y esto se logra por desnaturalización proteica o fraccionándose (Duran, 2004; Céspedes, 2005). 
En la carne marinada ocurre un incremento de iones de $\mathrm{H}+$ que afectan la carga eléctrica de los grupos ácidos y básicos de las cadenas laterales de los aminoácidos. Esta alteración de la carga superficial de las proteínas elimina las interacciones electrostáticas que estabilizan la estructura terciaria produciendo su precipitación (Lesk, 2000).

Durante el ahumado de la carne ocurre en forma simultánea un proceso térmico (Shweigert y Price, 1971). La intensificación de la acción del calor, que lleva consigo el ahumado, causa modificaciones en el sustrato (Girard, 1991) incluyendo la deshidratación. El incremento de la temperatura aumenta la energía cinética de las moléculas con lo que se desorganiza la envoltura acuosa de las proteínas y se desnaturalizan; así mismo, se destruyen las interacciones débiles y desorganiza la estructura de la proteína, de forma que el interior hidrofóbico interacciona con el medio acuoso produciendo agregación y precipitación de la proteína (Lesk, 2000).

En el curado seco se incrementa la concentración de sal (aumento de la fuerza iónica), lo que se traduce en una pérdida del equilibrio. Esto produce un flujo inicial de agua desde las proteínas del músculo hacia el medio, que luego se invierte debido a que la sal se difunde al interior, formando un complejo con las proteínas de la carne (Lawrie, 1998). Este efecto se debe a un incremento de la fuerza iónica del medio que provoca una disminución en el grado de hidratación de la proteína, ya que estos solutos compiten por el agua y rompen los puentes de hidrógeno o las interacciones electrostáticas, de forma que las moléculas se agregan y precipitan (Lesk, 2000).

El único grupo tratado donde no se inactivó la toxina fue el curado húmedo, a pesar de tener los mismos principios que el curado seco. Este tratamiento tiene la característica de presentar una difusión lenta de la solución salina en la carne, debido a solucio- nes relativamente débiles (6-9\%) como la aplicada por Lawrie (1998). Existe una relación lineal entre la concentración de sal y la velocidad de penetración (Girard, 1991). Los resultados obtenidos coinciden con lo reportado por Duran (2004), quien empleó una salmuera al $15 \%$.

La hipertermia observada post-inoculación en los conejos tratados fueron reportados en forma similar en otros estudios (Mansilla, 1993; Sam et al., 1998; Durán, 2004; Céspedes, 2005), y es atribuida a la toxina cuya presencia ocasiona la producción de pirógenos endógenos como mecanismo de defensa del organismo (Guinart y López, 1997). La disminución de la temperatura a las $8 \mathrm{~h}$ post-inoculación en los grupos curado húmedo y control positivo se debió al estado de shock en que se encontraban los conejos.

Los signos clínicos y muerte observados en los conejos del grupo control positivo y del curado húmedo fueron observados en diversos estudios previos (Leguía et al., 1988; Mansilla, 1993; Sam et al., 1998; Durán, 2004; Céspedes, 2005). Las lesiones macroscópicas encontradas en los conejos coinciden con las descritas por Mansilla (1993) y Sam et al. (1998).

Los resultados demuestran que todos los tratamientos químicos realizados en el presente estudio anulan la viabilidad de los macroquistes de $S$. aucheniae, y coinciden con otros reportes de la literatura (Durán, 2004; Fayer, 2004; Céspedes, 2005). Por otro lado, se conoce que la deshidratación, la temperatura alta y la concentración de solutos producen la muerte de cualquier organismo (Girard, 1991; Warris, 2003); es decir, la ausencia de esporoquistes en las heces de los perros que consumieron la carne infectada con macroquistes de $S$. aucheniae demostró la eficacia de los tratamientos químicos, ya que los esporoquistes se encontraron en las heces de los perros del grupo control positivo. 


\section{Conclusiones}

- El tratamiento de la carne de llama mediante los métodos químicos de marinado, curado seco y ahumado lograron detoxificar la toxina de los quistes de Sarcocystis aucheniae.

- El curado húmedo no logró detoxificar la toxina de los quistes de $S$. aucheniae.

- El marinado, curado seco, curado húmedo y ahumado afectaron la viabilidad de los macroquistes interrumpiendo el ciclo biológico de $S$. aucheniae.

\section{Literatura Citada}

1. Bravo, W.; E. Franco; J. Sumar. 1981. Rendimiento de canal en llamas. $4^{\mathrm{a}}$ Convención Internacional sobre Camélidos Sudamericanos. Punta Arenas, Chile.

2. Calderón, W.; S. Fernández-Baca. 1972. Peso vivo y rendimiento de canal de alpaca. Rev. Inv. Pec. IVITA 1(1): 5-9.

3. Castro, J. 1974. Sarcocystis aucheniae en llamas (Lama glama). Rev. Inv. Pec. IVITA 3(1): 91-92.

4. Céspedes, C. 2005. Saneamiento y detoxificación de la carne de alpaca con Sarcocystis mediante tratamientos físicos apropiados para uso doméstico. Tesis de Médico Veterinario. Facultad de Medicina Veterinaria, Univ. Nacional Mayor de San Marcos. Lima. 68 p.

5. Durán, J. 2004. Saneamiento y detoxificación de la carne de alpaca con Sarcocystis mediante la aplicación de tratamientos físico-químicos apropiados para uso doméstico. Tesis de Médico Veterinario. Facultad de Medicina Veterinaria, Univ. Nacional Mayor de San Marcos. Lima. 54 p.

6. Fayer, R. 2004. Sarcocystis spp. in human infections. Clin. Microbiol. Rev. 17(4): 894-902.
7. Girard, J.P. 1991. Tecnología de la carne y de los productos cárnicos. Ed. Acribia. Zaragoza. 250 p.

8. Guinart, N.; J. López. 1997. ¿Qué sabemos de la fiebre? Rev. Cubana Med. Gen. Integr. 13(2) [Internet]. [acceso 10 junio 2006]. Disponible en: http:// www.bvs.sld.cu/revistas/mgi/ vol13_2_97/mgi09297.htm

9. Hiepe, F.; L. Lietzke; G. Scheibner; R. Jungmann; T. Hiepe; T. Montag. 1981. Untersuchungen zur toxischen wirkung von extrankten aus Sarcocystis ovifelis-macrocysten auf kanichen. Mh. Vet. Med. 36: 908-910.

10. Lawrie, R. 1998. Ciencia de la carne. $3^{a}$ ed. p 187-281. Ed. Acribia. Zaragoza.

11. Leguía G.; C. Guerrero; R. Sam; R. Rosadio. 1988. Patología en Sarcocystis aucheniae en alpacas infectadas experimentalmente. X Congr. Pan. Cien. Vet. Lima, Perú.

12. Leguia, G.; N. Clavo. 1989. Sarcocystiosis o triquina. Bol. Div. No 7. IVITA-UNMSM-CICCS. p 12-14.

13. Lesk, A. 2000. Introduction to protein architecture the structural biology of proteins. Cambridge Institute for Medical Reserch. University of Cambridge.

14. Leyva, V. 1989. Sistemas de producción de alpacas. En: Simposio de producción de alpacas y llamas. XII Reunión APPA. Lima, Perú. p 157-168.

15. Mansilla, D. 1993. Efecto histopatológico del lisado de macroquistes de Sarcocystis aucheniae en ratones, conejos y cobayos. Tesis de Médico Veterinario. Facultad de Medicina Veterinaria, Univ. Nacional Mayor de San Marcos. Lima. 60 p.

16. [MINSA] Ministerio de Agricultura del Perú. 2004. Sector Pecuario en el Perú. [Internet]. [acceso 16 febrero 2006]. Disponible en: http:// www.minag.gob.pe/pecuario.shtml

17. Sam, R.; I, Mansilla; C. Morales; A. Ramírez. 1998. Efecto tóxico de macroquistes de Sarcocystis aucheniae 
en ratones, cobayos y conejos. Rev. Inv. Pec. IVITA 9(2): 11-18.

18. Shweigert, B.; J. Price. 1971. Ciencias de la carne y de los productos cárnicos. p 413-434. Ed. Acribia. Zaragoza.
19. Vilca, M.; L. Montoya. 1996. El beneficio de camélidos en camales municipales altoandinos. MV Rev. Cien. Vet. Lima 12(4): 23-28.

20. Warris. P. 2003. Ciencia de la carne. $p$ 204-212. Ed. Acribia. Zaragoza. 